\title{
Extracellular cold inducible RNA-binding protein mediates binge alcohol-induced brain hypoactivity and impaired cognition in mice
}

Asha Jacob ${ }^{1,4^{*}}$, Yilong Ma² Elham Nasiri ${ }^{3}$, Mahendar Ochani ${ }^{1}$, Joseph Carrion², Shichun Peng ${ }^{2}$, Max Brenner ${ }^{1,4}$, Patricio T. Huerta ${ }^{3,4}$ and Ping Wang ${ }^{1,5^{*}}$

\begin{abstract}
Background: Alcohol abuse affects the brain regions responsible for memory, coordination and emotional processing. Binge alcohol drinking has shown reductions in brain activity, but the molecular targets have not been completely elucidated. We hypothesized that brain cells respond to excessive alcohol by releasing a novel inflammatory mediator, called cold inducible RNA-binding protein (CIRP), which is critical for the decreased brain metabolic activity and impaired cognition.

Methods: Male wild type (WT) mice and mice deficient in $\mathrm{CIRP}\left(\mathrm{CIRP}^{-/-}\right)$were studied before and after exposure to binge alcohol level by assessment of relative brain glucose metabolism with fluorodeoxyglucose $\left({ }^{18} \mathrm{FDG}\right)$ and positron emission tomography (PET). Mice were also examined for object-place memory (OPM) and open field (OF) tasks.

Results: Statistical Parametric Analysis (SPM) of ${ }^{18}$ FDG-PET uptake revealed marked decreases in relative glucose metabolism in distinct brain regions of WT mice after binge alcohol. Regional analysis (post hoc) revealed that while activity in the temporal (secondary visual) and limbic (entorhinal/perirhinal) cortices was decreased in WT mice, relative glucose metabolic activity was less suppressed in the CIRP ${ }^{-1-}$ mice. Group and condition interaction analysis revealed differing responses in relative glucose metabolism (decrease in WT mice but increase in $\mathrm{CIRP}^{-/-}$mice) after alcohol in brain regions including the hippocampus and the cortical amygdala where the percent changes in metabolic activity correlated with changes in object discrimination performance. Behaviorally, alcohol-treated WT mice were impaired in exploring a repositioned object in the OPM task, and were more anxious in the OF task, whereas $\mathrm{CIRP}^{-1-}$ mice were not impaired in these tasks.

Conclusion: CIRP released from brain cells could be responsible for regional brain metabolic hypoactivity leading to cognitive impairment under binge alcohol conditions.
\end{abstract}

Keywords: CIRP, microPET, Fluorodeoxyglucose, Spatial memory, Hippocampus, Amygdala

\footnotetext{
*Correspondence: avarghes@northwell.edu; pwang@northwell.edu

${ }^{1}$ Immunology and Inflammation, Institute of Molecular Medicine, The

Feinstein Institutes for Medical Research, Northwell Health, Manhasset, NY,

USA

Full list of author information is available at the end of the article
}

(c) The Author(s). 2019 Open Access This article is distributed under the terms of the Creative Commons Attribution 4.0 International License (http://creativecommons.org/licenses/by/4.0/), which permits unrestricted use, distribution, and reproduction in any medium, provided you give appropriate credit to the original author(s) and the source, provide a link to the Creative Commons license, and indicate if changes were made. The Creative Commons Public Domain Dedication waiver (http://creativecommons.org/publicdomain/zero/1.0/) applies to the data made available in this article, unless otherwise stated. 


\section{Introduction}

Binge drinking is a popular mode of alcohol intake in young adults and the worldwide prevalence of such occurrence is about 16\% (Global status report on alcohol and health 2018, Geneva: World Health Organization, https://www.who.int/substance_abuse/ publications/global_alcohol_report/en/). The National Institute of Alcohol Abuse and Alcoholism (NIAAA) defines binge drinking as $\geq 4$ drinks for a woman and $\geq 5$ drinks for a man in about $2 \mathrm{~h}$. A blood alcohol concentration (BAC) of $17.4 \mathrm{mM}(0.08 \%)$ indicates excessive drinking and it is the legal BAC limit for driving in the US. Alcohol abuse negatively affects nearly all body tissues, and particularly the brain regions essential in memory, coordination and emotional processing (Guerri and Pascual 2010; Jacobus and Tapert 2013). Assessment of glucose metabolism has long been used to measure brain synaptic activity and function. Measurement of relative glucose utilization with fluorodeoxyglucose $\left({ }^{18} \mathrm{FDG}\right)$ and positron emission tomography (PET) has the potential to detect early brain dysfunction prior to any abnormal findings in neuropsychological testing (Thanos et al. 2008). ${ }^{18}$ FDG-PET imaging has been utilized to acquire neural snapshots of glucose metabolism in alcoholics and non-alcoholic healthy subjects (Volkow et al. 1992; Volkow et al. 1990). Oral administration of moderate to high doses of alcohol to non-alcoholic healthy adults markedly reduces their relative brain glucose metabolism (Schreckenberger et al. 2004; Volkow et al. 2006). However, the molecular targets for high alcohol in the brain have not been completely elucidated.

Cold inducible RNA-binding protein (CIRP) is a 172 amino acid protein belonging to a family of cold shock proteins (Nishiyama et al. 1997). It consists of a conserved N-terminal RNA binding domain, and a Cterminal glycine rich domain. Recent work has identified a novel function of CIRP in that, upon cellular stress, it is released from the cell and functions as a danger associated molecular pattern (DAMP) that promotes inflammation. Thus, extracellular CIRP represents a novel inflammatory mediator in stress conditions (Qiang et al. 2013). Functional brain imaging studies reveal that binge alcohol drinking in human adolescents causes structural alterations in distinct brain regions including the prefrontal cortex and the hippocampus (De Bellis et al. 2000; De Bellis et al. 2005). These structural anomalies have been correlated with cognitive impairment and neurophysiological abnormalities in young binge drinkers (De Bellis et al. 2000; De Bellis et al. 2005). Therefore, we hypothesize that binge alcohol increases the release of CIRP from brain cells and leads to decreased metabolic activity in regions associated with memory formation and cause impaired cognition. In the present study, to determine whether CIRP influences alcohol-mediated changes in brain metabolic activity, we exposed WT mice and mice deficient in CIRP $\left(\mathrm{CIRP}^{-/-}\right)$ to binge levels of alcohol followed by ${ }^{18} \mathrm{FDG}-\mathrm{PET}$ imaging to assess relative brain glucose metabolism. The same cohort of mice was assessed behaviorally with the object place memory (OPM) and open field (OF) tasks. In an additional cohort of WT and $\mathrm{CIRP}^{-/-}$mice, a testretest study was conducted where the mice underwent an identical experimental protocol with the exception of being treated with normal saline instead of alcohol.

\section{Materials and methods}

\section{Experimental animals}

Breeder pairs of $\mathrm{CIRP}^{-/-}$mice were a gift from Dr. Jun Fujita (Kyoto University, Japan). CIRP ${ }^{-1-}$ mice were 10x backcrossed on C57BL/6 background, and were bred in our animal facility (Qiang et al. 2013). Only male $\mathrm{CIRP}^{-/-}$animals aged $10-12$ weeks were used in this study. Male C57BL/6 mice aged 10-12 weeks (20-25 g, Taconic Labs, Albany, NY) were used as wild type (WT) controls. WT mice were acclimated to the environment for 5 days prior to any experiments. All mice were given food and water ad libitum. All animal protocols were performed based on the NIH Guide and Care of Laboratory Animals and were approved by the Institutional Animal Care and Use Committee of the Feinstein Institute for Medical Research.

\section{Model of binge alcohol in mice}

WT and $\mathrm{CIRP}^{-/-}$mice were anesthetized with $3 \%$ isoflurane inhalation and the right jugular vein was cannulated with a PE-10 catheter while maintaining anesthesia at 1$2 \%$. Mice were infused with a bolus of $1.5 \mathrm{~g}$ per $\mathrm{kg}$ ethanol $(23 \% \mathrm{v} / \mathrm{v})$ in normal saline through the cannula and the other end of the catheter was connected via a mouse harness (SAI infusion technologies, Libertyville, IL) to an infusion pump (KD Scientific, Holliston, MA). The harness allowed free movement of the animal. Mice were allowed to recover from anesthesia and the initial bolus infusion for $1 \mathrm{~h}$, after which they received $300 \mathrm{mg}$ per $\mathrm{kg}$ per $\mathrm{h}$ ethanol via the infusion pump for $15 \mathrm{~h}$ totaling $6 \mathrm{~g}$ per $\mathrm{kg}$ alcohol. Afterwards, they were lightly re-anesthetized, the cannula was removed and the vein ligated.

\section{MicroPET imaging}

Metabolic PET studies were performed following an established imaging protocol. Briefly, awake mice were given ${ }^{18} \mathrm{FDG}(0.34-1.0 \mathrm{mCi} / \mathrm{kg})$ intraperitoneally and were allowed unrestrained tracer uptake for $45 \mathrm{~min}$. Mice were then anesthetized with 2-3\% isoflurane inhalation and maintained at $1-2 \%$ while positioned in the Siemens Inveon PET scanner (Siemens AG, Munich, Germany). A 10-min static emission scan then was obtained within a field of view (FOV) of $12.7 \mathrm{~cm}$, with a 
full width half maximum (FWHM) resolution of $1.2 \mathrm{~mm}$ at the center of FOV and a slice thickness of $0.796 \mathrm{~mm}$. All mouse images were reconstructed using 3-dimensional Ordered Subset Expectation Maximization with Maximum A Priori (OSEM/3-D MAP). The resulting whole-body image had a matrix size of $128 \mathrm{~mm}$ X $128 \mathrm{~mm}$ X $159 \mathrm{~mm}$ and a pixel size of $0.776 \times 0.776 \times 0.796$ cubic millimeters, which is consistent with the image resolution of the microPET scanner. Whole blood glucose values were taken after each scan using a commercially available kit. ${ }^{18}$ FDG-PET images underwent a series of preprocessing procedures described below.

\section{Acquisition and preprocessing of images}

All mouse scan acquisitions were reconstructed using identical parameters and subsequently preprocessed on an Apple Mac Pro (Mac OS X 10.8.5, 2×2.93 Ghz 6-core intel Xeon microprocessors) using PMOD software version 3.3 (PMOD Technologies Ltd., Zurich, Switzerland). To extract the brain from the whole-body, each raw rodent image was cropped and re-oriented using a bounding box with a matrix size of $14.9 \mathrm{~mm} \times 20.7 \mathrm{~mm} \times 11.9 \mathrm{~mm}$, and of the identical voxel size as the unprocessed image. For anatomical alignment, all reconstructed images were placed into the mouse brain stereotaxic space (Paxinos and Franklin 2008) using ${ }^{18}$ FDG-baseline template available on the PMOD website as a fusion tool (http://www. pmod.com/files/download/v36/doc/pbas/4996.htm). The ${ }^{18}$ FDG baseline template (Mirrione et al. 2007) was created using male C57/BL6 mice aged 2-5 months (24-34 $\mathrm{g}$ ), and is based on a segmented MRI mouse brain dataset (Ma et al. 2005). The ${ }^{18}$ FDG template was opened in the PMOD reference window with activity set to milliCurie (mCi). Each reconstructed mouse scan file contained brain information for two mice, which necessitated loading image files in top-to-bottom configuration, and with the $\mathrm{Z}$-axis perpendicular to the coronal slice. With these settings in place, manual co-registration of images proceeded in the following order: for each file, the first (top) mouse brain image was manually aligned to the reference ${ }^{18} \mathrm{FDG}$ template and saved. The second (bottom) mouse brain was then manually flipped into position by mirroring $180^{\circ}$ along the $\mathrm{x}$-axis and registered to the ${ }^{18} \mathrm{FDG}$ template. Implementing this method for all mouse images permitted individual registration in sagittal, coronal, and transverse anatomical planes. In addition, mouse brain images were "skull stripped" to remove all non-brain metabolic regions in the following manner: Each file was loaded together with an ${ }^{18} \mathrm{FDG}$-brain mask file (created using the ${ }^{18} \mathrm{FDG}$ baseline template) in the PMOD manual co-registration window to eliminate all pixel values outside of the brain image $/{ }^{18}$ FDG-brain mask. The resulting images were converted into maps of standard uptake value (SUV) using injected dose and body weight for each animal to account for individual variability in injected radiotracer activity and weight. These images were then subsampled by approximately a factor of 10 to satisfy the theoretical requirement of Gaussian random field for subsequent brain mapping analysis described below with SPM.

\section{${ }^{18} \mathrm{FDG}$-PET image analysis}

PET images of SUV were analyzed using a mouse version of statistical parametric mapping software (SPM 5; Wellcome Department of Imaging Neuroscience, Institute of Neurology, London, UK) running in MATLAB 7.3 (The Mathworks Inc., MA). The baseline microPET brain images and those acquired post-alcohol were spatially aligned to each other, and then transformed into the standardized anatomical space using the ${ }^{18} \mathrm{FDG}$ mouse brain template described above. Each image was normalized by its global value to minimize interindividual variability and to increase statistical power. Analyses were performed on a voxel-by-voxel basis over the whole brain using general linear models implemented in SPM. A paired t-test model was first used to produce a set of brain regions in the WT mice showing highly significant decreases in globally normalized metabolic activity. Additionally, a two-way ANOVA was performed to reveal the effect of group $\mathrm{x}$ condition interaction. This analysis was conducted to examine explicitly the statistically significant group differences in regional metabolic activities between the two groups after treatment. The regions detected by each SPM run were then overlaid onto a mouse MRI brain template and identified using a mouse brain stereotaxic coordinates atlas (Paxinos and Franklin 2008). Globally normalized metabolic values were measured post-hoc in all PET images of WT and CIRP ${ }^{-/-}$mice over each of the regions defined by separate SPM analysis above. Changes in regional metabolism between pre- and post-alcohol conditions were computed using percent change [(post alcohol - pre alcohol) $\times 100 /$ pre-alcohol] in each animal.

\section{Behavioral testing}

One week prior to behavioral assessment, mice were maintained on a reverse schedule of $12-\mathrm{h}$ darkness $(07$ : 00 to 19:00) and 12-h light, with food and water ad libitum. For 3 days before testing, the mice were handled in daily sessions of 5-10 min. Animal handling and the initial testing were done during their dark circadian period. The mice were subjected to object-place memory (OPM) and open field (OF) tasks.

OPM testing was conducted as previously described (Faust et al. 2013). The apparatus consisted of a square base chamber $(40 \mathrm{~cm}$ on each side X $60 \mathrm{~cm}$ high) built of polyvinyl chloride, which was painted gray. An orange-red light bulb $(50 \mathrm{~W})$ illuminated the chamber from above. An infrared sensitive camera (Marshall 
Electronics, model CV502-MB) was mounted above the chamber and connected to the video input for the behavior tracking software (Ethovision XT11.5, Noldus), which tracked the mouse position at 30 frames per sec. The chamber and the objects were cleaned with $70 \%$ ethanol between subjects and groups. The OPM task consisted of a familiarization trial (T1), a sample trial (T2) and a choice trial (T3) interspersed by 10-min intervals in the familiar square base chamber. For T1, mice were placed in the empty chamber for $10 \mathrm{~min}$. For T2, mice explored the chamber for $10 \mathrm{~min}$ in the presence of two identical objects. For T3, mice explored the chamber for $10 \mathrm{~min}$ when one object remained at the same place as T2 $(\mathrm{S})$ but the second object was moved to a different location in the chamber $(\mathrm{M})$. The object exploration was measured with a software (Ethovision XT11.5, Noldus) algorithm that assigned a circular zone around each object and recorded the events in which the animal's snout was in close proximity $(<1 \mathrm{~cm})$ to the object. The sum of number of visits and the times spent on exploring both objects in T2 and T3 were also assessed. During T3, the discrimination ratio was calculated as "the time exploring the moved object $(\mathrm{M})$ minus that of the stable object (S) over the times of the sum of both objects" or "[(M-S) / $(M+S)]$ ".

For the OF task, the movements of the mice were automatically recorded for $10 \mathrm{~min}$ in the same chamber as the OPM task, and expressed as percent of total time the mice remained at the center of the chamber as opposed to the periphery, using an automated method ("arena setting tab" within Ethovision). The amount of time (sec) that the mice spent self-grooming was also measured during the OF task, using an automated method ("mouse behavior recognition module" within Ethovision).

\section{Experimental design}

On Day 1 of the experiment, mice underwent prealcohol behavior tests in the behavior suite located adjacent to the microPET imaging suite. The cyclotron radiotracer preparation facility is also located adjacent to the microPET suite, and prior arrangements were made to have the radiotracer prepared for use at 9:00 AM. Ten minutes after the baseline behavior test, the unanesthetized and unrestrained mice were injected intraperitoneally with the ${ }^{18} \mathrm{FDG}$ radiotracer in the microPET suite and $45 \mathrm{~min}$ allowed for ${ }^{18} \mathrm{FDG}$ uptake to take place. Intraperitoneal (I.P.) injection of ${ }^{18} \mathrm{FDG}$ is a valid alternative to intravenous (I.V.) injection, and it has been shown to have similar pharmacokinetics to IV administration in small animal studies (Wong et al. 2011). After allowing sufficient time for ${ }^{18} \mathrm{FDG}$ uptake, mice were anesthetized with $3 \%$ isoflurane inhalation and placed on the microPET scanner with $1-2 \%$ isoflurane anesthesia maintained during scanning. After scanning, the mice were allowed to remain in the climate and lightcontrolled room within the microPET suite for 24-30 h to allow for radiotracer decay. On Day 2, mice were returned to the vivarium and anesthetized with 3\% isoflurane inhalation, and the right jugular vein cannulated with a PE10 catheter while anesthesia was maintained at $1-2 \%$. They were then infused with alcohol bolus $(1.5 \mathrm{~g}$ per $\mathrm{kg}$ ) and allowed $1 \mathrm{~h}$ for recovery from anesthesia and the bolus injection. Afterwards, the other end of the PE10 catheter was connected to an infusion pump and infused with alcohol (300 mg per $\mathrm{kg}$ per h) for $15 \mathrm{~h}$. Mice were fitted with a harness allowing free movement of the animal during infusion (https://www.sai-infusion. com). At the end of $15 \mathrm{~h}$, they were lightly anesthetized and the catheter was removed and the vein ligated. Immediately after the infusion, on Day 3, the mice were transferred to the microPET suite and injected intraperitoneally (IP) with ${ }^{18}$ FDG. During the ${ }^{18}$ FDG uptake, mice were subjected to post-alcohol behavior tests in an identical manner as the pre-alcohol behavior tests. After $45 \mathrm{~min}$, the second microPET scan (post-alcohol) was acquired. Mice were then euthanized by $\mathrm{CO}_{2}$ asphyxiation (see Table 1 for a detailed timeline of each experiment). Using this timeline, experiments were performed in batches of 4 mice (2 WT and $2 \mathrm{CIRP}^{-/-}$mice) until completion of the study.

A total of 14 mice per group were included in the study. Despite our attempt to utilize the same mice for behavioral assessment and microPET analysis, 3 WT mice and $1 \mathrm{CIRP}^{-/-}$mouse died prior to the postalcohol scan and the second behavior analysis due to technical difficulties encountered during vein cannulation. In addition, behavioral testing failed in one $\mathrm{CIRP}^{-/-}$ mouse at the pre-alcohol test, and behavioral testing was not conducted in one WT mouse but the pre-alcohol and post-alcohol scans were completed.

All mice had ad libitum access to food and water throughout the experiment. During the $15 \mathrm{~h}$ continuous infusion, mice were awake and were given food pellets and water gels inside the cages to allow easy access to food and water. Those animals that died prior to the second scan and behavioral tests died during vein cannulation. There were no mortality events during continuous infusion or during pre- or post-alcohol scanning periods. A separate cohort of mice $(n=3)$ received $1.5 \mathrm{~g}$ per $\mathrm{kg}$ alcohol bolus and $1 \mathrm{~h}$ later, they were re-anesthetized with $3 \%$ isoflurane inhalation, euthanized by $\mathrm{CO}_{2}$ asphyxiation and blood collected via cardiac puncture. Blood alcohol concentration (BAC) was measured immediately using a commercially available kit (Pointe Scientific). BAC reached to $37-38 \mathrm{mM}(0.17 \%)$ at $1 \mathrm{~h}$ after the initial bolus dose, which constitutes binge alcohol levels. In an additional cohort of WT and $\mathrm{CIRP}^{-/-}$mice ( $n=5 /$ group), a test and re-test study was conducted. 
Table 1 Timeline for each experiment. Abbreviations: FDG, fluorodeoxyglucose; PET, positron emission tomography

\begin{tabular}{lll}
\hline DAY & Time & Procedure \\
\hline 1 & $9: 00-10: 00$ & Object Place Memory task \#1 \\
1 & $10: 10-10: 55$ & FDG injection and uptake \\
1 & $10: 55-11: 05$ & Pre-alcohol microPET scan under anesthesia \\
$1-2$ & $11: 05-16: 00$ & Tracer decay for $29-30 \mathrm{~h}$ \\
2 & $16: 00-18: 00$ & Vein cannulation, alcohol bolus (i.v.) under anesthesia \\
2 & $18: 00-19: 00$ & Recovery \\
$2-3$ & $19: 00-9: 00$ & Alcohol infusion via pump, without anesthesia \\
3 & $9: 00-9: 10$ & Vein ligation after 15 $\mathrm{h}$ under light anesthesia \\
3 & $9: 20-10: 05$ & FDG injection \\
3 & $9: 20-10: 05$ & Object Place Memory task \#2 (assessed during FDG uptake) \\
3 & $10: 05-10: 15$ & Post-alcohol microPET scan under anesthesia \\
3 & $10: 20$ & Euthanasia \\
\hline
\end{tabular}

The same experimental protocol and timeline as described earlier were followed with the exception that all mice were treated with normal saline instead of alcohol.

\section{Statistical analysis}

Data of regional glucose metabolism or measures of behavioral testing were compared separately between conditions and groups. Changes between conditions were assessed by paired $t$-tests and differences between groups were evaluated by unpaired $t$-tests and MannWhitney test. Analysis for group and conditions interaction was conducted using two-way analysis of variance (ANOVA). Correlation analysis of regional metabolic values among different regions and with spatial cognition tasks was conducted by Pearson correlation.

\section{Results}

Relative brain glucose metabolic activity was decreased regionally in mice after binge alcohol

The analysis of WT brains consisted of defining regions of metabolic changes between the pre-alcohol and postalcohol treatment conditions, by using a paired t-test model with the display parameter (Threshold $(\mathrm{T})=4.297$, $P<0.001)$. We found several brain structures that showed decreased glucose metabolism, which were identified based on the 3D mouse brain atlas (Fig. 1a). Specific brain regions, their peak coordinates and $t$-value (actual thresholds) are presented (Tables 2 and 3).

\section{CIRP deficiency attenuated the decrease in brain metabolic activity observed in WT mice after binge alcohol}

We observed, using the region-of-interest analysis, that the percent (\%) changes of the globally normalized metabolic values were decreased to a smaller degree in $\mathrm{CIRP}^{-/-}$ mice compared to WT mice. Among these regions, the \% changes were significantly smaller in $\mathrm{CIRP}^{-/-}$mice for the following cortical regions: agranular insular, secondary visual, primary somatosensory, and reached a trend level in entorhinal/perirhinal cortex (Fig. 1b, Table 4). In a correlation analysis where the data were combined between WT and $\mathrm{CIRP}^{-/-}$mice $(n=22)$, changes in regional metabolic values in the entorhinal/perirhinal cortex correlated with those in agranular insular cortex and primary somatosensory cortex $(r>0.5 ; P<0.02)$.

CIRP deficiency reversed the decrease in brain metabolic activity observed in WT mice after binge alcohol

The percent changes of the globally normalized metabolic values from WT mice and $\mathrm{CIRP}^{-/-}$mice were analyzed in SPM using a two-way ANOVA to examine the effect of group $x$ condition interaction. When the display parameter was set to Threshold $=2.42, P<0.01$, the analysis produced 7 regions where metabolic activity decreased in WT mice but increased in $\mathrm{CIRP}^{-/-}$mice (Fig. 2a, b, Table 5). The same 7 regions were also significant with the display parameter set to $P<0.005$. The two-way ANOVA revealed similar regions to the original analysis including the insular, visual and primary somatosensory cortices. Interestingly, this analysis identified two additional regions, i.e., the hippocampus and the cortical amygdala (specifically, the posteromedial cortical amygdaloid area, PMCoAA). In a correlation analysis when the data were combined between WT and CIRP ${ }^{-1-}$ mice $(n=17)$, strong correlations between regions were identified in treatment induced changes in relative metabolic values. The fimbria of the hippocampus correlated with PMCoAA $(r>0.5 ; P=0.02)$, and primary somatosensory cortex, barrel field $(\mathrm{r}>0.4 ; P=0.05)$.

Regional brain metabolic activity was similar in WT and CIRP $^{-1-}$ mice after saline control treatment

Normalized glucose metabolic values were computed post-hoc in test-retest acquisitions using the same regions 
A
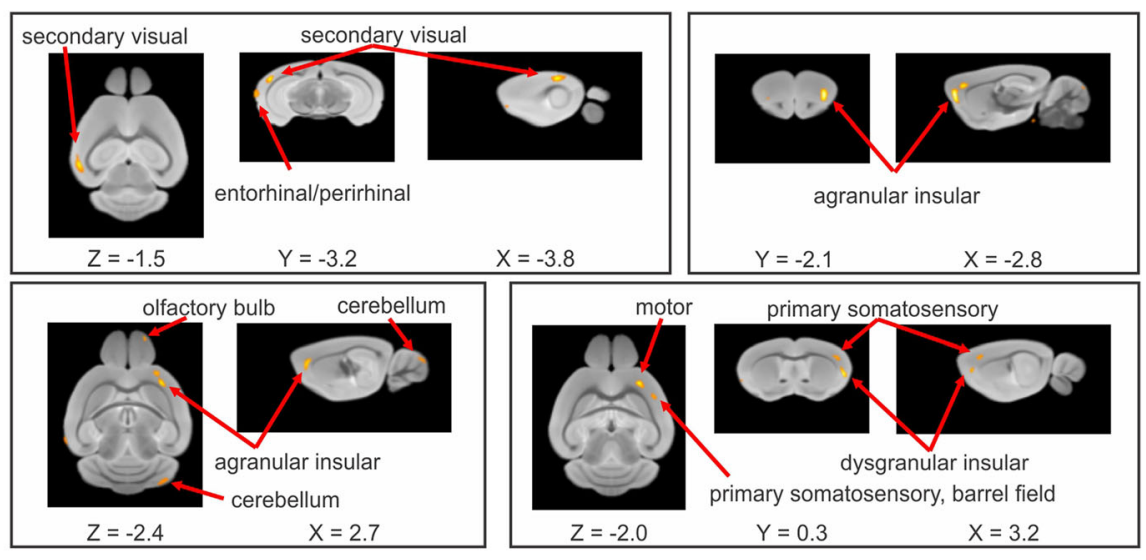

B

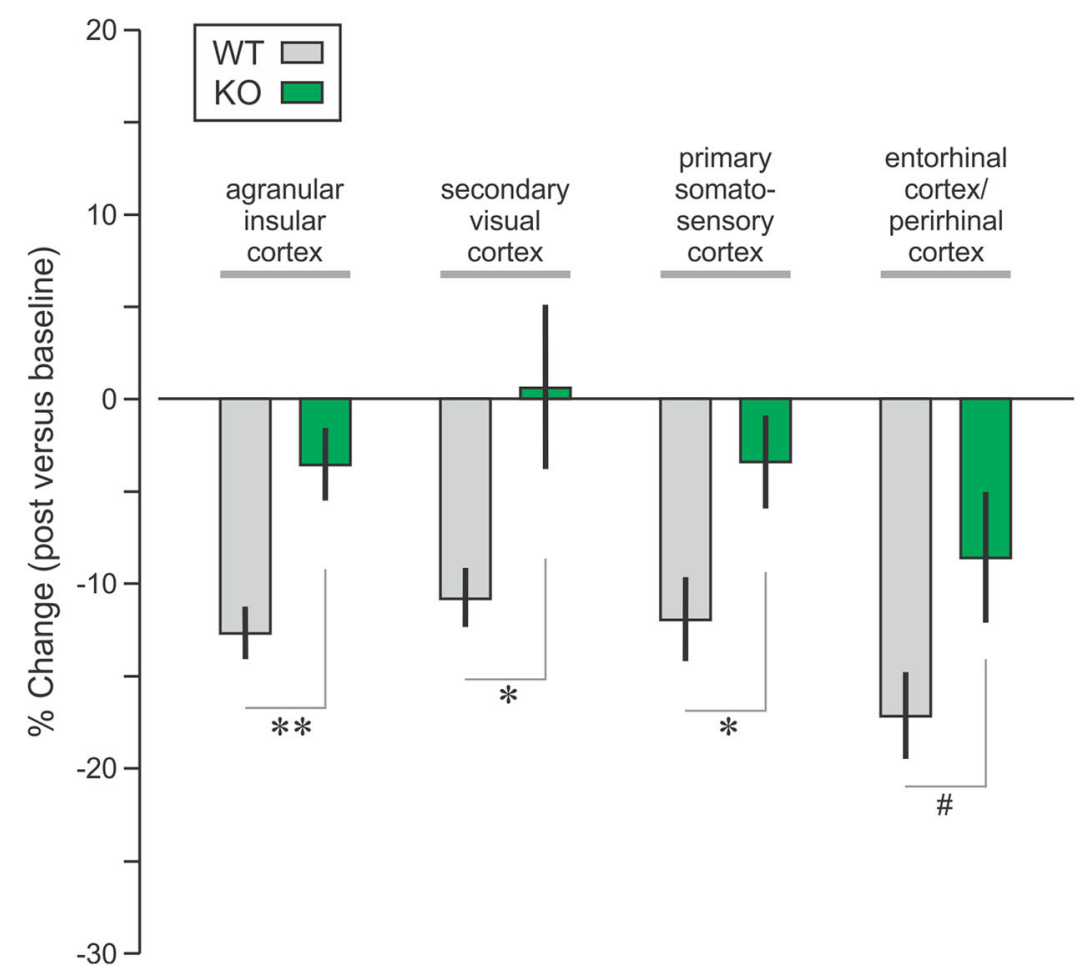

Fig. 1 Regional metabolic activity was decreased in the WT mice after binge alcohol and deficiency in CIRP attenuated these decreases in metabolic activities. a ${ }^{18}$ FDG-PET images from WT mice were analyzed by SPM8 software. Regions with decreased metabolic activity were aligned onto a standard mouse MRI brain template and regions anatomically identified based on a three-dimensional mouse brain atlas (Paxinos and Franklin 2008). Using bregma as the reference point, the Y-coordinate corresponds to the anterior-posterior (AP) distance from bregma in the coronal plane, the X-coordinate corresponds to the sagittal or mediolateral (ML) plane, and the Z-coordinate corresponds to the axial or dorsoventral (DV) views of the brain regions. b Percent changes in globally normalized metabolic values in WT and CIRP ${ }^{-1-}$ (KO) mice of specific regions identified in the $\mathrm{WT}$ group. Data are expressed as mean $\pm \mathrm{SE}^{*}{ }^{*} P<0.05,{ }^{*} P<0.001$; \# $P=0.069$, KO vs. WT mice of respective regions

that were defined using paired t-test in the WT group (Table 2) and ANOVA in the WT and $\mathrm{CIRP}^{-/-}$groups (Table 3) respectively. The post-hoc analysis for regions in Table 2 showed that regional ${ }^{18} \mathrm{FDG}$ uptake values were stable in the WT or $\mathrm{CIRP}^{-/-}$mice $(P>0.05, P>0.08$, paired t-tests) in all regions except primary somatosensory cortex (barrel field), where the retest values were lower $(P$ $<0.008)$ than those in the test scans (Table 4). Similar analyses for regions in Table 3 were conducted on regions identified in the ANOVA (Table 5). Interestingly, with the exception of the same region, primary somatosensory cortex (barrel field), $(P<0.001)$, no significant difference in percent changes were observed between pre- and postsaline in any other region in the WT or $\mathrm{CIRP}^{-/-}$mice $(P>0.05, P>0.12$, paired t-test). Nevertheless, no group differences were detected in any regions in terms of percent 
Table 2 Regional metabolic activity was decreased in WT mice after binge alcohol. Regions identified by SPM with decreases in metabolic activity in WT mice post-alcohol $(T=4.3, P=0.001)$

\begin{tabular}{|c|c|c|c|c|c|c|}
\hline Regions & Anatomical Regions & $X(\mathrm{~mm})$ & $Y(\mathrm{~mm})$ & $\mathrm{Z}(\mathrm{mm})$ & Threshold & Voxels \\
\hline$\overline{\mathrm{R} 11}$ & Agranular insular cortex, dorsal part & 2.2 & 2.1 & -2.8 & 10.07 & 2677 \\
\hline R13 & Secondary visual cortex, lateral area & -3.8 & -3.2 & -1.5 & 7.04 & 819 \\
\hline R14 & Glomerular layer of the olfactory bulb & 1.3 & 4.8 & -2.9 & 6.93 & 1567 \\
\hline R15 & Entorhinal/perirhinal cortex & -4.7 & -3.6 & -2.9 & 6.65 & 1181 \\
\hline R17 & Spinal trigeminal tract & 1.8 & -7.8 & -4.6 & 6.4 & 945 \\
\hline R18 & Spinocerebellar tract & -1.5 & -8.1 & -5.8 & 5.86 & 2714 \\
\hline R19 & Primary somatosensory cortex, barrel field & 3.2 & 0.3 & -2.0 & 5.24 & 142 \\
\hline
\end{tabular}

changes in regional glucose metabolic values between postand pre-saline conditions in both analyses $(P>0.08$, unpaired t-tests).

The possible influence of plasma glucose levels on the observed results was also analyzed. This is important not only to indicate rigorous quality control of the study, but also to support the robustness of regionally specific differences in cerebral glucose metabolism detected in the brain between the treatment conditions and animal groups. Indeed, no treatment-related changes were found for the injected dose, plasma glucose, global SUV values before and after correction with plasma glucose concentration in WT $(P>0.17$, paired t-test $)$ or $\mathrm{CIRP}^{-/-}$ $(P>0.07)$ group or in the combined group $(P>0.11)$. No group differences were detected in these variables except in global SUV values corrected for plasma glucose at post-alcohol treatment $(P<0.05$, unpaired t-test). In the test re-test study, no treatment-related changes were found for the injected dose, plasma glucose, global SUV values before and after correction with plasma glucose concentration in WT $(P>0.06$, paired t-test $)$ or $\mathrm{CIRP}^{-/-}$ $(P>0.35)$ group or in the combined group $(P>0.11)$. No group differences were detected in these variables in the WT $(P>0.09$, unpaired t-test $)$ and $\operatorname{CIRP}^{-/-}(P>0.14)$ groups. No group differences were seen $(P>0.07$, unpaired t-test) in these variables in terms of \% changes between pre- and post-saline conditions. A detailed statistical analysis is shown in Table 6.
CIRP deficiency prevented the impaired spatial cognition observed in WT mice after binge alcohol exposure

For the OPM task (Fig. 3), a positive discrimination ratio indicates the preferential exploration of a moved object and spatial memory. The total time exploring objects during the sample phase and test phases were significantly decreased in the WT mice post-alcohol but in the $\mathrm{CIRP}^{-/-}$mice, these times were not altered from the pre-alcohol tests (Fig. 3b). Both WT and $\mathrm{CIRP}^{-/-}$mice had similarly positive discrimination ratios at prealcohol. The alcohol treatment did not perturb spatial cognition in $\mathrm{CIRP}^{-/-}$mice as they continued to examine a recently moved object during the OPM task $(T=0.15$, $P=0.87$, t test). Conversely, WT mice showed significantly impaired OPM performance $(T=3.9, P=8.75 \times$ $10^{-4}$, t test) (Fig. 3c). A two-way ANOVA of the discrimination ratios revealed a significant difference by genotype $(F=5.22, P=0.027)$ as well as genotype $\mathrm{x}$ alcohol treatment $(F=4.21, P=0.021)$.

\section{CIRP deficiency inhibited the altered OF behavior shown by WT mice after binge alcohol exposure}

WT and CIRP $^{-1-}$ mice spent similar time in the center and periphery of the chamber at pre-alcohol. However, the alcohol treatment resulted in $\mathrm{CIRP}^{-/-}$mice displaying higher exploration of the center of the OF than the WT group, demonstrating their familiarity to the chamber (Fig. 4b). The total distances traversed were significantly

Table 3 Regional metabolic activity was decreased in WT mice after binge alcohol. Regions identified using two way ANOVA by SPM with decreases in metabolic activity in WT mice post-alcohol $(T=2.4, P<0.01)$

\begin{tabular}{|c|c|c|c|c|c|c|c|}
\hline Regions & Anatomical Regions & $X(\mathrm{~mm})$ & $Y(\mathrm{~mm})$ & $\mathrm{Z}(\mathrm{mm})$ & Threshold & Voxels & $P$ \\
\hline R1 & Olfactory bulb, glomerular layer & -1.9 & 3.8 & -2.4 & 3.99 & 429 & 0.001 \\
\hline R2 & Agranular insular cortex, ventral part & 1.7 & 2.6 & -2.6 & 3.38 & 936 & 0.001 \\
\hline R3 & Cerebellum, third lobule of cerebellar vermis & -1.5 & -5.9 & -2.9 & 3.23 & 297 & 0.001 \\
\hline R4 & Posteriomedial cortical amygdaloid area & -2.7 & -3.3 & -5.3 & 3.22 & 243 & 0.001 \\
\hline R5 & Hippocampus, fimbria & -2.7 & -2.0 & -3.9 & 3.22 & 948 & 0.001 \\
\hline R6 & Primary visual cortex & -4.1 & -4.0 & -1.5 & 3.15 & 359 & 0.002 \\
\hline R7 & Primary somatosensory cortex, barrel field & 2.9 & 0.3 & -2.0 & 3.13 & 596 & 0.002 \\
\hline
\end{tabular}


Table 4 Regional metabolic activity in regions identified in the WT mice after binge alcohol. Percent changes in regional metabolic activity in the WT and $\mathrm{CIRP}^{-1-}$ mice treated with alcohol or normal saline (mean $\pm \mathrm{SE}$ ). ${ }^{*} P<0.05$ and ${ }^{* *} P<0.01$ between pre- and post-saline treatment within groups

\begin{tabular}{|c|c|c|c|c|c|c|c|}
\hline \multirow[t]{2}{*}{ Regions } & \multirow[t]{2}{*}{ Anatomical Regions } & \multicolumn{3}{|l|}{ Alcohol } & \multicolumn{3}{|l|}{ Saline } \\
\hline & & WT (\% change) & KO (\% change) & $P$ & WT (\% change) & KO (\% change) & $P$ \\
\hline$\overline{\mathrm{R} 11}$ & Agranular insular cortex, dorsal part & $-12.7 \pm 1.4$ & $-3.5 \pm 1.9$ & 0.001 & $-3.6 \pm 3.1$ & $-1.3 \pm 3.1$ & 0.84 \\
\hline R13 & Secondary visual cortex, lateral area & $-10.8 \pm 1.6$ & $0.6 \pm 4.4$ & 0.029 & $1.0 \pm 5.0$ & $7.7 \pm 7.1$ & 0.46 \\
\hline R14 & Glomerular layer of the olfactory bulb & $-16.1 \pm 2.4$ & $-15.5 \pm 2.8$ & 0.887 & $10.6 \pm 10.3$ & $-12.5 \pm 5.1$ & 0.08 \\
\hline R15 & Entorhinal/perirhinal cortex & $-17.2 \pm 2.4$ & $-8.6 \pm 3.5$ & 0.069 & $-11.1 \pm 3.9$ & $-7.2 \pm 7.1$ & 0.64 \\
\hline R17 & Spinal trigeminal tract & $-15.8 \pm 2.3$ & $-16.5 \pm 3.2$ & 0.501 & $-2.9 \pm 6.7$ & $-19.0 \pm 5.1$ & 0.09 \\
\hline R18 & Spinocerebellar tract & $-31.7 \pm 4.9$ & $-32.9 \pm 6.1$ & 0.878 & $0.03 \pm 13.2$ & $-7.2 \pm 14.0$ & 0.72 \\
\hline R19 & Primary somatosensory cortex, barrel field & $-11.9 \pm 2.3$ & $-3.4 \pm 2.4$ & 0.02 & $-10.3 \pm 1.9^{* *}$ & $-10.9 \pm 3.7^{*}$ & 0.88 \\
\hline
\end{tabular}

decreased from pre-alcohol to post-alcohol in both WT and $\mathrm{CIRP}^{-1-}$ mice, but the decrease was smaller in $\mathrm{CIRP}^{-/-}$mice (Fig. 4c). A two-way ANOVA of the distance demonstrated no difference by genotype $(F=3.41, P$ $=0.07)$, but significant variance by alcohol treatment $(F=$ 24.36, $\left.P=1 \times 10^{-5}\right)$ as well as genotype $\mathrm{x}$ treatment $(F=$ 13.56, $P=2.2 \times 10^{-5}$ ). Additionally, both groups showed increased levels of self-grooming after the alcohol treatment (Fig. 4d).

\section{Regional metabolic activity is significantly correlated with} spatial cognition after binge alcohol exposure

In a correlation analysis where the data were combined between WT and $\mathrm{CIRP}^{-/-}$mice $(n=17)$, there was a strong correlation between the changes in discrimination ratio and the percent changes in metabolic activity the fimbria of the hippocampus $(r=0.73, P<0.001)$ and in the PMCoAA ( $r=0.53, P=0.03)$ (Fig. 5).

\section{Discussion}

Binge level of alcohol administration in healthy nonalcoholic subjects showed decreased brain glucose metabolism using ${ }^{18}$ FDG-PET (Volkow et al. 2006) but similar studies have not been done in rodent models of binge alcohol exposure. The objective of the current study was to first identify regions in WT mice where brain glucose metabolism decreased due to binge alcohol exposure, and then determine whether those specific regions were less suppressed in the CIRP ${ }^{-/-}$mice after alcohol. In order to address the first objective, SPM analysis with paired $t$-test using general linear models were performed on the data obtained from the WT mice during pre- and post-alcohol. This model produced a set of brain regions of ${ }^{18}$ FDG uptake in the WT mice showing highly significant decreases in globally normalized metabolic activity. The regions were overlaid onto a mouse MRI brain template, and identified using an anatomical mouse brain atlas (Paxinos and Franklin 2008). To address the second objective, globally normalized metabolic values of WT and $\mathrm{CIRP}^{-/-}$brain regions were analyzed post hoc in each of the regions identified by SPM analysis. The initial analysis revealed marked differences between the two animal groups in several regions, including the temporal (secondary visual) cortex and a trend difference in the limbic (entorhinal/perirhinal) cortex. This simple strategy tested the main hypothesis of neuroprotection in $\mathrm{CIRP}^{-1-}$ mice versus WT mice following binge alcohol exposure. The SPM analysis was then performed using two-way ANOVA to reveal the effect of

Table 5 Regional metabolic activity in regions identified by the two way ANOVA analysis. Percent changes in regional metabolic activity in the WT and $\mathrm{CIRP}^{-/-}$mice treated with alcohol or normal saline (mean \pm SE). ${ }^{* *} P<0.01$ between pre- and post-saline treatment within groups

\begin{tabular}{|c|c|c|c|c|c|c|c|}
\hline \multirow[t]{2}{*}{ Regions } & \multirow[t]{2}{*}{ Anatomical Regions } & \multicolumn{3}{|l|}{ Alcohol } & \multicolumn{3}{|l|}{ Saline } \\
\hline & & WT (\% change) & $\mathrm{KO}$ (\% change) & $P$ & WT (\% change) & KO (\% change) & $P$ \\
\hline R1 & Olfactory bulb, glomerular layer & $-14.5 \pm 5.1$ & $5.2 \pm 3.1$ & 0.004 & $13.1 \pm 12.4$ & $10.5 \pm 12.2$ & 0.89 \\
\hline R2 & Agranular insular cortex, ventral part & $-10.1 \pm 4.0$ & $4.7 \pm 2.0$ & 0.002 & $-5.8 \pm 4.8$ & $4.7 \pm 3.8$ & 0.13 \\
\hline R3 & Cerebellum, third lobule of cerebellar vermis & $1.5 \pm 2.9$ & $12.3 \pm 2.1$ & 0.006 & $-0.3 \pm 4.8$ & $10.3 \pm 5.4$ & 0.18 \\
\hline R4 & Posteriomedial cortical amygdaloid area & $-11.3 \pm 5.5$ & $3.1 \pm 3.2$ & 0.03 & $1.2 \pm 3.8$ & $2.1 \pm 6.4$ & 0.91 \\
\hline R5 & Hippocampus, fimbria & $-5.3 \pm 2.5$ & $5.1 \pm 2.1$ & 0.004 & $2.8 \pm 4.0$ & $1.1 \pm 3.4$ & 0.75 \\
\hline R6 & Primary visual cortex & $-18.6 \pm 5.1$ & $-1.1 \pm 4.8$ & 0.022 & $4.2 \pm 5.5$ & $14.4 \pm 8.2$ & 0.1 \\
\hline R7 & Primary somatosensory cortex, barrel field & $-8.5 \pm 2.3$ & $2.1 \pm 2.5$ & 0.006 & $-10.0 \pm 0.9^{*}$ & $-6.6 \pm 3.1$ & 0.34 \\
\hline
\end{tabular}


A
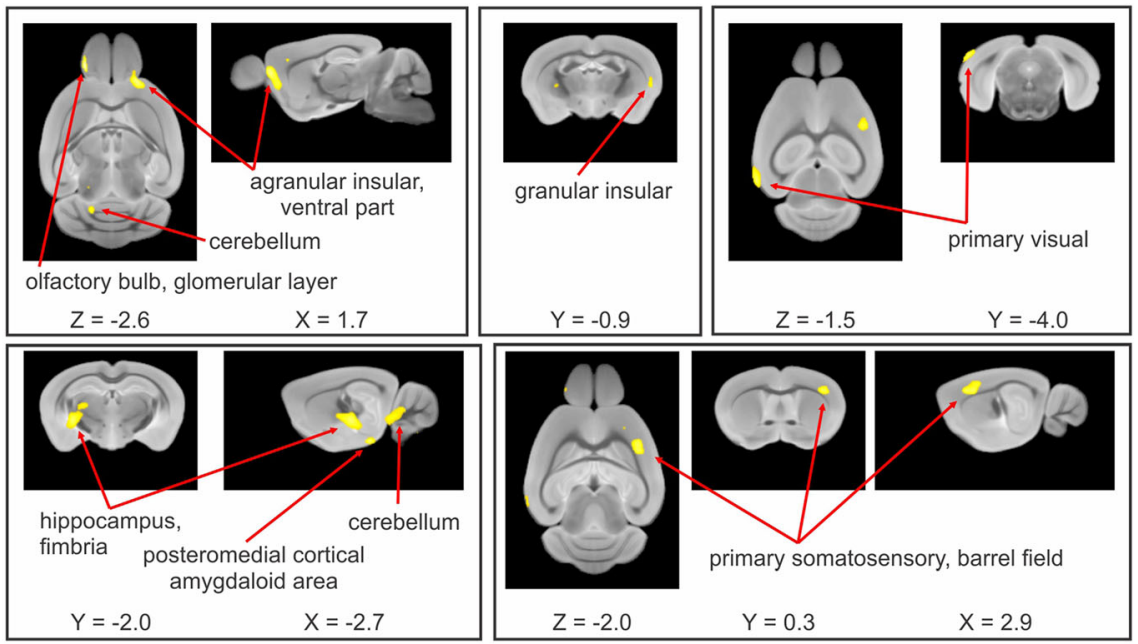

B

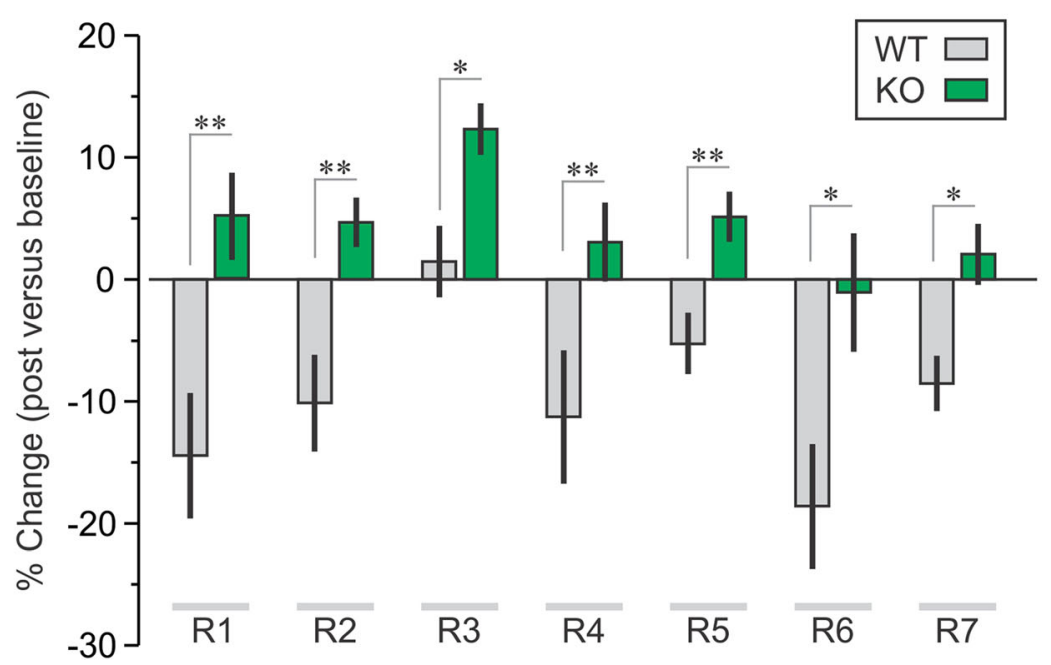

Fig. 2 Deficiency in CIRP reversed the decreased regional metabolic activity in the WT mice after binge alcohol. a Regions identified by SPM analysis using two way ANOVA in which metabolic activity was decreased in WT mice but increased in KO mice during post-alcohol were aligned to mouse MRI brain template and regions anatomically identified based on a three dimensional mouse brain atlas (Paxinos and Franklin 2008). $\mathbf{b}$ Percent changes in globally normalized metabolic values decreased in WT mice but increased in $\mathrm{CIRP}^{-/-}(\mathrm{KO})$ mice over specific regions revealed by the two-way ANOVA. The regions are as follows: R1-Olfactory bulb, glomerular layer, R2-agranular insular cortex, ventral part, R3-cerebellum, 3rd lobule of cerebellar vermis, R4- posteromedial cortical amygdaloid area, R5-hippocampus, fimbria, R6-primary visual cortex, R7-primary somatosensory cortex, barrel field. See Table 2 for the stereotaxic coordinates and anatomic volumes of these regions. Data are expressed as mean $\pm \mathrm{SE}^{*}{ }^{*} P<0.05,{ }^{* *} P<0.005, \mathrm{KO}$ vs. WT mice of respective regions

group $\mathrm{X}$ condition interaction. The two-way ANOVA revealed similar regions of ${ }^{18} \mathrm{FDG}$ uptake to the original analysis including the insular, visual and primary somatosensory cortices. Interestingly, this analysis identified additional regions such as the hippocampus and the cortical amygdala.

The present study showed that binge alcohol exposure in WT mice leads to decreases in relative brain glucose $\left({ }^{18} \mathrm{FDG}\right)$ uptake within several neocortical areas, including the temporal lobe. The medial temporal lobe consists of the hippocampal region and the adjacent perirhinal, entorhinal and the parahippocampal cortices, which are essential for spatial and episodic memory (Squire et al. 2004). In rodent models, dysfunction of these regions results in impaired object place memory (Faust et al. 2013). Acute ethanol exposure can also result in deficient spatial reference memory (Matthews et al. 1995; Matthews et al. 1999; Matthews and Morrow 2000). We found that binge alcohol-exposed WT mice showed abnormalities when exploring a moved object in the OPM task and when exploring an open field. In contrast, similar exposure to alcohol in $\mathrm{CIRP}^{-/-}$mice did not lead to impairments in the OPM and the OF tasks. Pearson correlation analysis between the changes in 
Table 6 Absolute SUV values corrected for plasma glucose concentration. Global SUV values corrected for glucose levels at postalcohol between WT and $\mathrm{CIRP}^{-1-}$ mice are significant ( $P=0.034$, unpaired t-test). No group differences were seen in global SUV values in percent changes between pre- and post-saline treatment $(P>0.07$, unpaired test)

\begin{tabular}{|c|c|c|c|c|c|}
\hline & Weight (g) & $\begin{array}{l}\text { Injected dose } \\
(\mathrm{mCi})\end{array}$ & $\begin{array}{l}\text { Blood glucose (mg/ } \\
\text { dl) }\end{array}$ & Global SUV & $\begin{array}{l}\text { Global SUV x blood } \\
\text { glucose }\end{array}$ \\
\hline \multicolumn{6}{|l|}{ Cohort 1} \\
\hline WT-baseline & $25.2 \pm 0.53$ & $0.98 \pm 0.21$ & $209 \pm 10.0$ & $84.62 \pm 5.87$ & $16.84 \pm 1.68$ \\
\hline WT-post-alcohol & $23.6 \pm 0.43$ & $0.67 \pm 0.10$ & $203 \pm 11.9$ & $82.86 \pm 8.58$ & $14.88 \pm 1.05$ \\
\hline WT baseline vs. post-alcohol ( $P$ value) & 0.029 & 0.218 & 0.807 & 0.780 & 0.171 \\
\hline KO-baseline & $28.6 \pm 1.11$ & $1.00 \pm 0.20$ & $212 \pm 19.0$ & $91.48 \pm 7.82$ & $18.90 \pm 1.60$ \\
\hline KO-post-alcohol & $27.8 \pm 1.23$ & $0.79 \pm 0.11$ & $193 \pm 7.80$ & $\begin{array}{l}108.47 \pm \\
9.51\end{array}$ & $21.18 \pm 2.42$ \\
\hline KO baseline vs. KO post-alcohol ( $P$ value) & 0.181 & 0.348 & 0.421 & 0.072 & 0.528 \\
\hline WT + KO (baseline) & $27.0 \pm 0.7$ & $0.99 \pm 0.14$ & $211 \pm 12.0$ & $88.37 \pm 4.98$ & $18.08 \pm 1.27$ \\
\hline WT + KO (post-alcohol) & $25.8 \pm 0.81$ & $0.73 \pm 0.07$ & $198 \pm 6.67$ & $96.28 \pm 6.90$ & $18.20 \pm 1.52$ \\
\hline $\begin{array}{l}W T+K O \text { baseline vs } W T+K O \text { post-alcohol (P } \\
\text { value) }\end{array}$ & 0.009 & 0.113 & 0.403 & 0.146 & 0.991 \\
\hline \multicolumn{6}{|l|}{ Cohort 2} \\
\hline WT-baseline & $\begin{array}{l}23.60 \pm \\
0.81\end{array}$ & $0.67 \pm 0.04$ & $184 \pm 11.8$ & $\begin{array}{l}99.32 \pm \\
10.86\end{array}$ & $16.41 \pm 2.31$ \\
\hline WT-post-saline & $\begin{array}{l}24.40 \pm \\
0.60\end{array}$ & $0.83 \pm 0.04$ & $175 \pm 14.6$ & $67.07 \pm 7.09$ & $12.09 \pm 0.55$ \\
\hline WT baseline vs. post-saline ( $P$ value) & 0.242 & 0.09 & 0.73 & 0.058 & 0.211 \\
\hline KO-baseline & $23.0 \pm 0.55$ & $0.61 \pm 0.04$ & $190 \pm 12.4$ & $71.80 \pm 9.29$ & $12.66 \pm 0.56$ \\
\hline KO-post-saline & $23.4 \pm 0.40$ & $0.66 \pm 0.11$ & $197 \pm 9.5$ & $72.57 \pm 4.67$ & $13.58 \pm 0.72$ \\
\hline KO baseline vs. KO post-saline ( $\mathrm{P}$ value) & 0.374 & 0.678 & 0.499 & 0.934 & 0.346 \\
\hline $\mathrm{WT}+\mathrm{KO}$ (baseline) & $\begin{array}{l}23.30 \pm \\
0.47\end{array}$ & $0.64 \pm 0.03$ & $187 \pm 7.8$ & $85.56 \pm 8.15$ & $14.53 \pm 1.35$ \\
\hline $\mathrm{WT}+\mathrm{KO}$ (post-saline) & $\begin{array}{l}23.90 \pm \\
7.56\end{array}$ & $0.74 \pm 0.23$ & $186 \pm 9.0$ & $69.82 \pm 4.11$ & $12.83 \pm 4.54$ \\
\hline $\begin{array}{l}W T+K O \text { baseline vs } W T+K O \text { post-saline ( } P \\
\text { value) }\end{array}$ & 0.111 & 0.135 & 0.377 & 0.114 & 0.322 \\
\hline
\end{tabular}

relative metabolism in the 7 regions identified by two-way ANOVA and the changes in OPM ratio showed strong correlations in the hippocampus and the cortical amygdala. The revelation that the metabolic activity is decreased in the hippocampus after binge alcohol further strengthens the observation of the significant decrease in the OPM ratio in WT mice. The data also revealed a strong correlation between regions identified in the twoway ANOVA analysis. Interestingly, the changes in regional metabolic activities in the hippocampus correlated with those in the cortical amygdala. Therefore, the current study strongly suggests that binge alcohol exposure decreases metabolic activity in brain regions associated with memory and cognition of WT mice, whereas these activities are relatively preserved in the $\mathrm{CIRP}^{-/-}$mice, indicating a crucial role of CIRP during binge alcohol exposure.

Since its discovery in 1997, diverse functions of CIRP have been increasingly recognized, from being an RNA chaperone, to a mediator of inflammation (Nishiyama et al. 1997; Sheikh et al. 1997; Xue et al. 1999; Gualerzi et al. 2003; Wellmann et al. 2004; Morf et al. 2012; Qiang et al. 2013). CIRP is expressed at low levels in nearly all tissue, and upon cellular stress, it can be translocated to the cytosol where it binds to 3 ' regions of target mRNAs to either increase or decrease their translation. This interaction regulates cell proliferation, survival, apoptosis and the circadian rhythm. While CIRP may function as a protective protein intracellularly, it can be released from cells and the extracellular CIRP may work as a DAMP that promotes inflammation (Qiang et al. 2013; Rajayer et al. 2013; Zhou et al. 2013). Since in the present study, $\mathrm{CIRP}^{-/-}$mice were protected from the decreases in metabolic brain activity and cognitive deficits that occur after binge alcohol exposure, it can be speculated that the observed protection is due to the elimination of either the intracellular or extracellular CIRP.

A major limitation to our study is that we did not discriminate whether the observed decrease in metabolic 

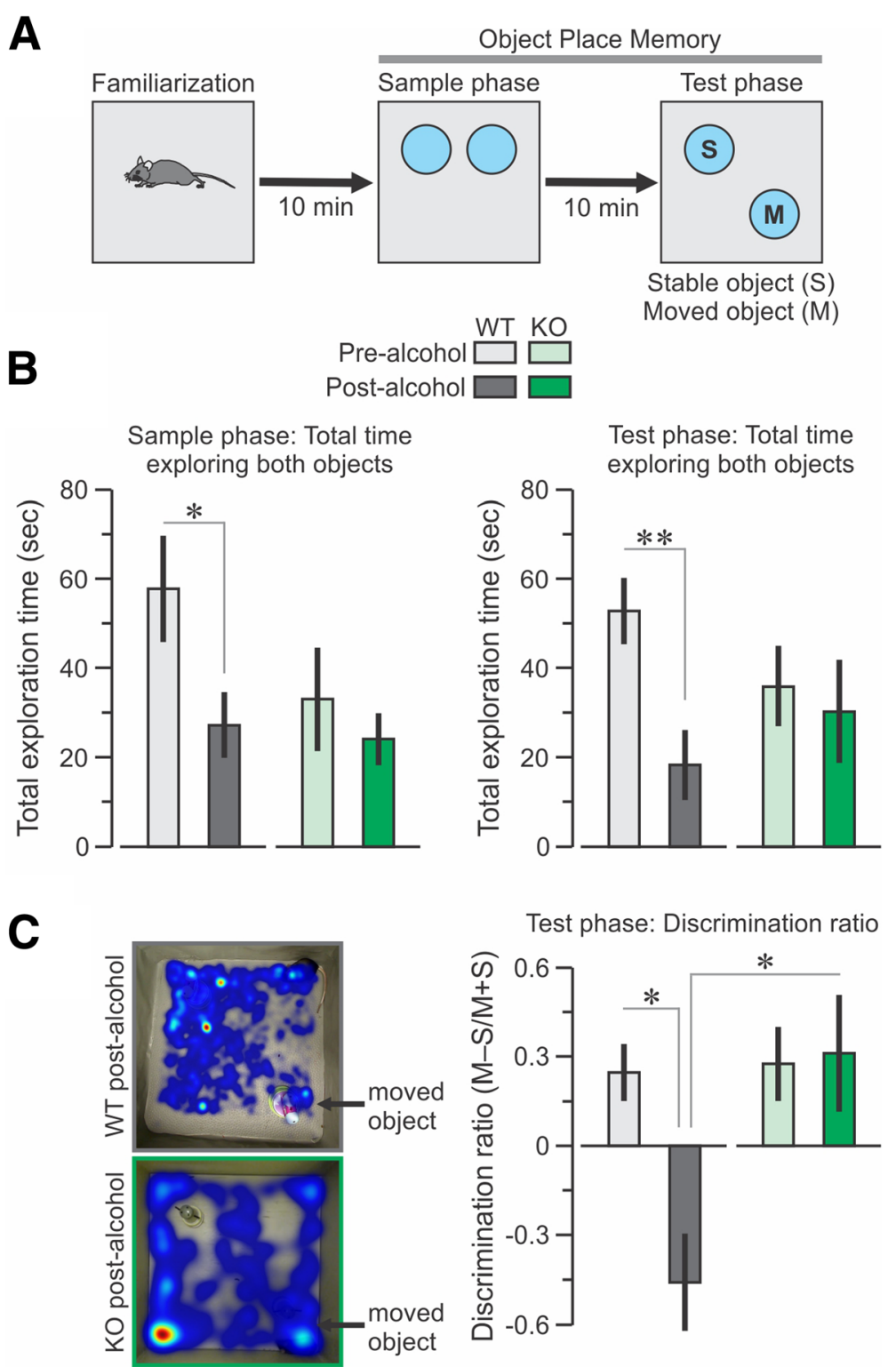

Test phase: Discrimination ratio

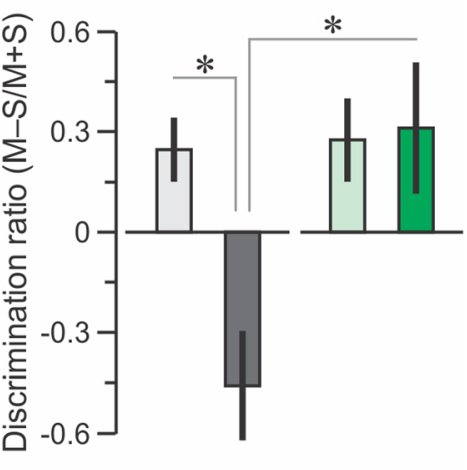

Fig. 3 Deficiency in CIRP prevented the decreased spatial cognition observed in the WT mice after binge alcohol. a Scheme for the object-place memory (OPM) task in which a mouse explores two objects, with one object being moved in the last session. $\mathbf{b}$ Total time exploring both objects during sample phase and test phases. c Left, representative heat maps of WT and CIRP ${ }^{-1-}$ mice exploring the moved object, Right, discrimination ratio (moved minus stable object over moved plus stable object $[(\mathrm{M}-\mathrm{S}) /(\mathrm{M}+\mathrm{S})]$ ) between WT and CIRP ${ }^{-/-}$mice at pre-alcohol and post-alcohol conditions. Data are expressed as mean $\pm \mathrm{SE}$; * $P<0.05$; ** $P<0.005$ by t-test

activity in WT mice was due to extracellular or intracellular effects of CIRP. A previous study that included surgical intensive-care patients, as well as rodent models of hemorrhagic shock and sepsis, found detectable levels of CIRP protein in the blood (Qiang et al. 2013). Blocking CIRP, either by neutralizing antibody or the use of $\mathrm{CIRP}^{-1-}$ mice, showed decreased inflammation and improved survival in several rodent models of inflammatory diseases including hemorrhagic shock and sepsis (Qiang et al. 2013; Godwin et al. 2015; Cen et al. 2016). In vitro experiments with macrophage cells exposed to hypoxia/reoxygenation, or LPS stimulation, have shown that CIRP is translocated from nucleus to cytosol and secreted into the medium (Qiang et al. 2013). In addition, exogenous administration of recombinant murine CIRP in healthy rats increased markers of liver injury and inflammatory cytokines (TNF- $\alpha$, IL-6 and HMGB1), indicating that extracellular CIRP is an inflammatory mediator that can trigger inflammation under stress conditions (Qiang et al. 2013). The extracellular action of CIRP is mediated by TLR4/MD2 and acts as a DAMP to promote inflammation (Qiang et al. 2013). Released 
A
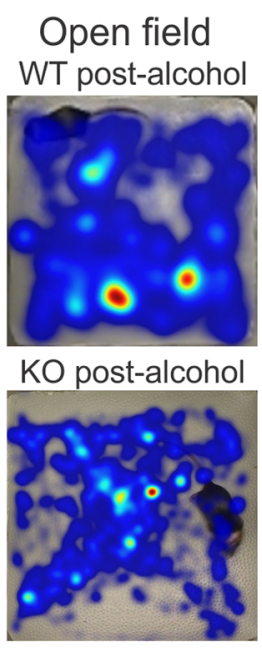

C Open field distance
WT KO
Pre-alcohol $\square \square$
Post-alcohol $\square \square$

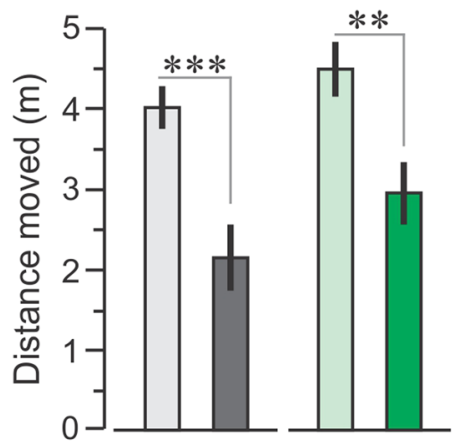

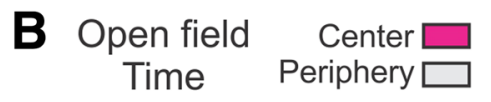
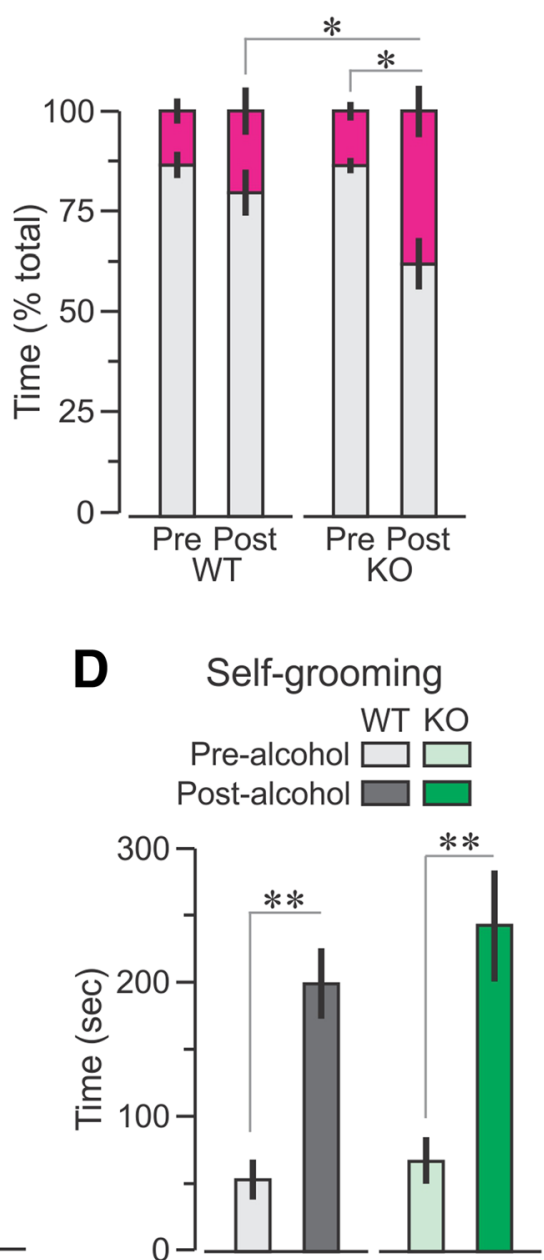

Fig. 4 Deficiency in CIRP inhibited the altered open field behavior exhibited by WT mice. a Representative heat map of WT and CIRP ${ }^{-/-}$mice exploring the chamber. $\mathbf{b}$ Percent time spent exploring either the center or periphery of the chamber. $\mathbf{c}$ Total distance traversed during the test. d Time spent for self-grooming during the OF tasks. Data are expressed as mean $\pm \mathrm{SE} ;{ }^{*} P<0.05$; ${ }^{* *} P<0.005$, ${ }^{* * *} P<0.001$ by t-test

CIRP has been shown to induce endothelial cell pyroptosis and initiate adaptive T-cell responses (Yang et al. 2016; Bolognese et al. 2018). CIRP can also be released from BV2 microglia cells in response to alcohol (Rajayer et al. 2013). These previous findings strongly suggest that extracellular CIRP could be responsible for the binge alcohol-induced regionally specific brain hypoactivity leading to impaired cognition. A behavioral limitation is that the testing was solely selected based on previous reports (Garcia-Moreno and Cimadevilla 2012). Specific behavioral analysis related to the regions identified in the ${ }^{18}$ FDG-PET analysis should provide insights into the role of CIRP and behavioral dysfunction in binge alcohol exposure.

It is important to examine several experimental factors that may impact the methodology of PET imaging acquisition and analysis. With the exception of a slight decrease in body weight in the post-alcohol WT mice $(P$ $=0.03$ ), there were no treatment related changes in whole blood glucose values, injected dose or global SUV values before and after correction with plasma glucose concentrations in either the WT mice, $\mathrm{CIRP}^{-1-}$, or in the combined group. No group differences were detected in these variables except in global SUV values corrected for plasma glucose levels at post-treatment $(P=0.03)$. These observations confirmed adequate quality control for the imaging portion of the study, and justified the use of globally normalized metabolic values in the analysis of the imaging data. Of note, it is not useful to show specific metabolic characteristics in individual animals due to the limited signal to noise ratios present in each ${ }^{18}$ FDG-PET image. Therefore, regionally specific 

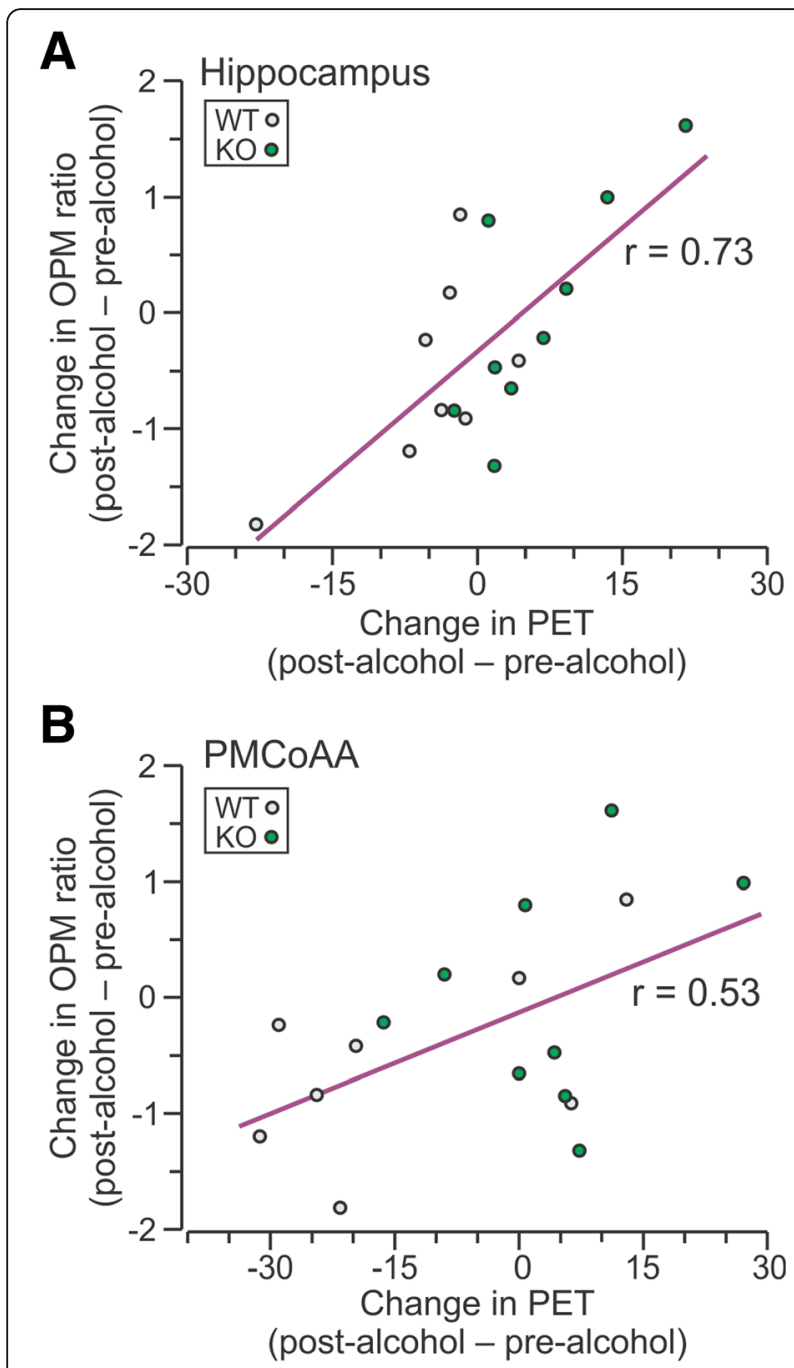

Fig. 5 Regional metabolic activity is correlated with spatial cognition after binge alcohol. Pearson correlation analysis of percent changes in globally normalized metabolic values in the WT (open circles) and $\mathrm{CIRP}^{-/-}$mice (closed circles) with changes in OPM ratio of the hippocampus $(r=0.73, P<0.001)$ and posteromedial cortical amygdaloid area (PMCoAA; $r=0.53, P=0.03$ )

effects can be detected only by performing brainmapping analysis with SPM as shown in this study. We focused on the group $x$ treatment interaction to interrogate the main hypothesis of the study that brain glucose metabolism is less suppressed in $\mathrm{CIRP}^{-/-}$mice than WT mice following binge alcohol exposure.

It can be speculated that the difference between preand post-alcohol scans are due to simple repetition effects or multiple anesthesia exposures, and not specific for ethanol. To this end, a test-retest study was performed in WT and $\mathrm{CIRP}^{-/-}$mice that followed the same experimental protocols, but were treated with saline in both groups. No treatment-related changes were observed in WT or CIRP ${ }^{-/-}$group in regard to the injected dose, plasma glucose or global SUV values before and after plasma glucose correction. No group differences were detected in these variables in the WT and $\mathrm{CIRP}^{-/-}$ groups, nor were there differences in terms of \% changes between pre- and post-saline conditions. The regional metabolic values were stable in all regions except the primary somatosensory cortex (barrel field) in pre- and post-saline in both groups. Nevertheless, no differences were observed between groups for percent changes in the test/retest saline group in any of the regions identified in the alcohol treated groups. Therefore, it is highly unlikely that the differences observed between pre- and post-alcohol scans are simply due to repetition effects.

For the initial behavior analysis, the light-dark cycles were reversed so that the testing was done during the dark circadian period. It can be speculated that the reverse cycle impacted the outcome of the study. However, in order to conduct behavioral studies, it was important to reverse their light-dark cycles, otherwise, the experiment had to be done in the night, i.e., during their day. Since our objective was to correlate the microPET data with the behavior, the behavior tasks were conducted in conjunction with the microPET scans, i.e., 9:00 AM. After the basal behavior and basal scan, mice were kept in the microPET suite for 24-30 h undisturbed with the normal 12-h light/dark cycles. Afterwards, the mice underwent alcohol infusion in the aid of a mouse harness so that they were again undisturbed for $15 \mathrm{~h}$ with the normal 12-h light/dark cycles. It is expected that stress of the reverse light-dark cycle and sleep deprivation could similarly impact both groups. Therefore, it is highly unlikely that the changes seen in the behavior between groups and conditions are simply due to experimental stress. In addition, the initial behavioral testing was done prior to IP injection of FDG to minimize radioactivity exposure to the personnel. After $15 \mathrm{~h}$, mice underwent behavior during FDG uptake to prevent time lapse between behavior and microPET scans post-alcohol. Since the same experimental procedure was followed for both groups, the IP injection could not have impacted the observed changes between groups and conditions. Separate experiments conducted each for behavior and microPET scan with the two groups could have circumvented these experimental technical discrepancies encountered in this study. However, choosing to conduct both behavior and FDG-PET in the same mice allowed to perform the correlational analysis between the two parameters which was the fundamental reason for the current experimental design.

The dose of $6 \mathrm{~g} / \mathrm{kg}$ alcohol could be considered as too high dose to model binge alcohol drinking. However, mice were injected with $1.5 \mathrm{~g} / \mathrm{kg}$ alcohol bolus for a period of $20 \mathrm{~min}$. This initial dose is the maximum tolerated bolus dose for a mouse and at $1 \mathrm{~h}$ after the alcohol 
bolus, the blood alcohol was $38 \mathrm{mM}$ which constituted the binge alcohol level. Although continuous infusion for $15 \mathrm{~h}$ at $300 \mathrm{mg} / \mathrm{kg} / \mathrm{h}$ totals the alcohol dose to $6 \mathrm{~g} / \mathrm{kg}$, the actual blood alcohol level is expected to decrease even from the bolus dose due to rapid metabolism of alcohol in mice. In the future, we plan to use additional lower doses of bolus to ascertain the minimum dose necessary to influence brain hypoactivity and impaired cognition.

The primary objective of this study was to test the hypothesis that $\mathrm{CIRP}^{-1-}$ mice have a neuroprotective effect when compared to WT mice in the context of binge alcohol exposure. In the present study we have fulfilled our objective with two approaches: (1) we have identified hypometabolic brain regions in WT mice whose neurobiological substrates remain intact; (2) we have identified hypometabolic brain regions using ANOVA to tease out the interaction between WT and $\mathrm{CIRP}^{-/-}$mice. Regional metabolic values extracted from these sets of regions were then compared across the experimental conditions and animal groups. Both approaches revealed regional brain metabolic decreases in the WT that were less suppressed metabolically in the $\mathrm{CIRP}^{-1-}$ mice after binge alcohol exposure. Further studies are needed to replicate our findings in large samples, and to investigate possible mechanisms of spatial co-variation using more powerful multivariate brain mapping analysis.

\section{Conclusion}

These data suggest that extracellular CIRP released from brain cells could be responsible for brain metabolic hypoactivity and impaired cognition in binge alcohol exposure. Blocking released CIRP from brain cells could be a potential therapeutic strategy for binge alcohol drinking.

\begin{abstract}
Abbreviations
${ }^{18}$ FDG: 18-Fluorodeoxyglucose; BAC: Blood alcohol concentration; CIRP: Cold inducible RNA binding protein; $\mathrm{CIRP}^{-1}$ : Mice deficient in CIRP; DAMP: Danger associated molecular pattern; FOV: Field of view; HMGB1: High mobility group box 1; IL-6: Interleukin-6; mCi: milliCurie; NIAAA: National Institute of Alcohol Abuse and Alcoholism; OF: Open field; OPM: Object place memory; PET: Positron emission tomography; PMCoAA: Posteriomedial cortical amygdaloid area; SPM: Statistical parametric mapping; SUV: Standard uptake value; TNF-a: Tumor necrosis factor-alpha; WT: Wild type
\end{abstract}

\section{Acknowledgments}

The authors thank Drs. Stephen Dewey, Christine Metz and Wayne Chaung for their helpful suggestions on this study.

\section{Funding}

This study is in part supported by the National Institute of Health grants, R21AA021496 (Wang P) and R21AA025574 (Varghese (Jacob A) and Wang P). This work was also partly supported by NIH grants 5P01Al102852 (Huerta PT) and 5P01Al073693 (Huerta PT).

\section{Availability of data and materials \\ Agreed.}

\section{Authors' contributions}

$A J, M B, P T H$, and PW designed the experiments. AJ, YM, EN, MO, JC, SP, MB, and PTH performed experiments and analyzed the data. AJ, YM, and PTH made the final figures. AJ, YM, JC, MB, PTH and PW wrote the manuscript. All authors approved the manuscript.

\section{Ethics approval}

All animal protocols were performed based on the NIH Guide and Care of Laboratory Animals and were approved by the Institutional Animal Care and Use Committee of the Feinstein Institute for Medical Research.

\section{Consent for publication}

All authors have read and provided consent for publication of this study.

\section{Competing interests}

The authors declare that they have no competing interests.

\section{Publisher's Note}

Springer Nature remains neutral with regard to jurisdictional claims in published maps and institutional affiliations.

\section{Author details}

${ }^{1}$ Immunology and Inflammation, Institute of Molecular Medicine, The Feinstein Institutes for Medical Research, Northwell Health, Manhasset, NY, USA. ${ }^{2}$ Center for Neurosciences, Institute of Molecular Medicine, The Feinstein Institutes for Medical Research, Northwell Health, Manhasset, NY, USA. ${ }^{3}$ Laboratory of Immune \& Neural Networks, Institute of Molecular Medicine, The Feinstein Institutes for Medical Research, Northwell Health, Manhasset, NY, USA. ${ }^{4}$ Department of Molecular Medicine, Donald and Barbara Zucker School of Medicine at Hofstra/Northwell, Hempstead, NY, USA. ${ }^{5}$ Departments of Surgery and Molecular Medicine, Donald and Barbara Zucker School of Medicine at Hofstra/Northwell, Hempstead, NY, USA.

Received: 18 April 2019 Accepted: 15 May 2019

Published online: 30 May 2019

\section{References}

Bolognese AC, Sharma A, Yang WL, Nicastro J, Coppa GF, Wang P. Cold-inducible RNA-binding protein activates splenic T cells during sepsis in a TLR4dependent manner. Cell Mol Immunol. 2018;15(1):38-47.

Cen C, Yang WL, Yen HT, Nicastro JM, Coppa GF, Wang P. Deficiency of coldinducible ribonucleic acid-binding protein reduces renal injury after ischemia-reperfusion. Surgery. 2016;160(2):473-83.

De Bellis MD, Clark DB, Beers SR, Soloff PH, Boring AM, Hall J, Kersh A, Keshavan MS. Hippocampal volume in adolescent-onset alcohol use disorders. Am J Psychiatry. 2000;157(5):737-44.

De Bellis MD, Narasimhan A, Thatcher DL, Keshavan MS, Soloff P, Clark DB. Prefrontal cortex, thalamus, and cerebellar volumes in adolescents and young adults with adolescent-onset alcohol use disorders and comorbid mental disorders. Alcohol Clin Exp Res. 2005;29(9):1590-600.

Faust TW, Robbiati S, Huerta TS, Huerta PT. Dynamic NMDAR-mediated properties of place cells during the object place memory task. Front Behav Neurosci. 2013;7:202.

Garcia-Moreno LM, Cimadevilla JM. Acute and chronic ethanol intake: effects on spatial and non-spatial memory in rats. Alcohol. 2012;46(8):757-62.

Godwin A, Yang WL, Sharma A, Khader A, Wang Z, Zhang F, Nicastro J, Coppa GF, Wang P. Blocking cold-inducible RNA-binding protein protects liver from ischemia-reperfusion injury. Shock. 2015;43(1):24-30.

Gualerzi CO, Giuliodori AM, Pon CL. Transcriptional and post-transcriptional control of cold-shock genes. J Mol Biol. 2003;331(3):527-39.

Guerri C, Pascual M. Mechanisms involved in the neurotoxic, cognitive, and neurobehavioral effects of alcohol consumption during adolescence. Alcohol. 2010;44(1):15-26

Jacobus J, Tapert SF. Neurotoxic effects of alcohol in adolescence. Annu Rev Clin Psychol. 2013;9:703-21.

Ma Y, Hof PR, Grant SC, Blackband SJ, Bennett R, Slatest L, et al. A threedimensional digital atlas database of the adult C57BL/6J mouse brain by magnetic resonance microscopy. Neuroscience. 2005;135(4):1203-15.

Matthews DB, Ilgen M, White AM, Best PJ. Acute ethanol administration impairs spatial performance while facilitating nonspatial performance in rats. Neurobiol Learn Mem. 1999;72(3):169-79.

Matthews DB, Morrow AL. Effects of acute and chronic ethanol exposure on spatial cognitive processing and hippocampal function in the rat. Hippocampus. 2000;10(1):122-30. 
Matthews DB, Simson PE, Best PJ. Acute ethanol impairs spatial memory but not stimulus/response memory in the rat. Alcohol Clin Exp Res. 1995;19(4):902-9.

Mirrione MM, Schiffer WK, Fowler JS, Alexoff DL, Dewey SL, Tsirka SE. A novel approach for imaging brain-behavior relationships in mice reveals unexpected metabolic patterns during seizures in the absence of tissue plasminogen activator. Neuroimage. 2007;38(1):34-42.

Morf J, Rey G, Schneider K, Stratmann M, Fujita J, Naef F, Schibler U. Coldinducible RNA-binding protein modulates circadian gene expression posttranscriptionally. Science. 2012;338(6105):379-83.

Nishiyama H, Higashitsuji H, Yokoi H, Itoh K, Danno S, Matsuda T, Fujita J. Cloning and characterization of human CIRP (cold-inducible RNA-binding protein) CDNA and chromosomal assignment of the gene. Gene. 1997;204(1-2):115-20.

Paxinos G, Franklin KJ. The mouse brain in stereotaxic coordinates. 3rd ed. New York: Academic Press; 2008.

Qiang X, Yang WL, Wu R, Zhou M, Jacob A, Dong W, et al. Cold-inducible RNAbinding protein (CIRP) triggers inflammatory responses in hemorrhagic shock and sepsis. Nat Med. 2013;19(11):1489-95.

Rajayer SR, Jacob A, Yang WL, Zhou M, Chaung W, Wang P. Cold-inducible RNAbinding protein is an important mediator of alcohol-induced brain inflammation. PLoS One. 2013;8(11):e79430.

Schreckenberger M, Amberg R, Scheurich A, Lochmann M, Tichy W, Klega A, et al. Acute alcohol effects on neuronal and attentional processing: striatal reward system and inhibitory sensory interactions under acute ethanol challenge. Neuropsychopharmacology. 2004;29(8):1527-37.

Sheikh MS, Carrier F, Papathanasiou MA, Hollander MC, Zhan Q, Yu K, Fornace AJ Jr. Identification of several human homologs of hamster DNA damageinducible transcripts. Cloning and characterization of a novel UV-inducible CDNA that codes for a putative RNA-binding protein. J Biol Chem. 1997; 272(42):26720-6.

Squire LR, Stark CE, Clark RE. The medial temporal lobe. Annu Rev Neurosci. 2004;27:279-06.

Thanos PK, Wang GJ, Volkow ND. Positron emission tomography as a tool for studying alcohol abuse. Alcohol Res Health. 2008;31(3):233-7.

Volkow ND, Hitzemann R, Wang GJ, Fowler JS, Burr G, Pascani K, et al. Decreased brain metabolism in neurologically intact healthy alcoholics. Am J Psychiatry. 1992;149(8):1016-22.

Volkow ND, Hitzemann R, Wolf AP, Logan J, Fowler JS, Christman D, et al. Acute effects of ethanol on regional brain glucose metabolism and transport. Psychiatry Res. 1990;35(1):39-48.

Volkow ND, Wang GJ, Franceschi D, Fowler JS, Thanos PP, Maynard L, et al. Low doses of alcohol substantially decrease glucose metabolism in the human brain. Neuroimage. 2006;29(1):295-301.

Wellmann S, Buhrer C, Moderegger E, Zelmer A, Kirschner R, Koehne P, et al. Oxygen-regulated expression of the RNA-binding proteins RBM3 and CIRP by a HIF-1-independent mechanism. J Cell Sci. 2004;117(Pt 9:1785-94.

Wong KP, Sha W, Zhang X, Huang SC. Effects of administration route, dietary condition, and blood glucose level on kinetics and uptake of 18F-FDG in mice. J Nucl Med. 2011:52(5):800-7.

Xue JH, Nonoguchi K, Fukumoto M, Sato T, Nishiyama H, Higashitsuji H, et al. Effects of ischemia and $\mathrm{H}_{2} \mathrm{O} 2$ on the cold stress protein CIRP expression in rat neuronal cells. Free Radic Biol Med. 1999;27(11-12):1238-44.

Yang WL, Sharma A, Wang Z, Li Z, Fan J, Wang P. Cold-inducible RNA-binding protein causes endothelial dysfunction via activation of Nlrp3 inflammasome. Sci Rep. 2016;6:26571.

Zhou M, Wang CM, Yang WL, Wang P. Microglial CD14 activated by iNOS contributes to neuroinflammation in cerebral ischemia. Brain Res. 2013; 1506:105-14

Ready to submit your research? Choose BMC and benefit from:

- fast, convenient online submission

- thorough peer review by experienced researchers in your field

- rapid publication on acceptance

- support for research data, including large and complex data types

- gold Open Access which fosters wider collaboration and increased citations

- maximum visibility for your research: over $100 \mathrm{M}$ website views per year

At BMC, research is always in progress.

Learn more biomedcentral.com/submissions 